\title{
A process model on P2P lending
}

\author{
Huaiqing Wang, Kun Chen", Wei Zhu and Zhenxia Song
}

\author{
* Correspondence: chenk@sustc. \\ edu.cn \\ Department of Financial \\ Mathematics and Engineering, \\ South University of Science and \\ Technology, Shenzhen, Guangdong, \\ China
}

\begin{abstract}
Background: Online peer-to-peer lending (P2P lending) is booming as the popularity of e-finance. To develop a conceptual model for the P2P lending process is great valuable for managers to tack the issues of marketing, management and operation.

Methods: In this paper, we focus on the P2P lending process model and provide a comparative analysis comparing with traditional bank loan process.

Results: Firstly, our model shows that the information flow in P2P lending is more frequent and transparent. Secondly, the model reveals that P2P lending uses a quite different credit audition method, which relies on information and the decision model in the P2P systems. Thirdly, the loan management is not complete normally in P2P lending, because most P2P companies do not have the post-loan records of borrowers.

Conclusions: These findings inspire future studies and practices on P2P lending process and key technologies.

Keywords: P2P landing; E-finance; Process model
\end{abstract}

\section{Introduction}

Online peer-to-peer lending (P2P lending) is booming as the popularity of e-finance (Kiisel 2013; Berger and Gleisner 2009). This innovative financial activity refers to unsecured direct loans between lenders and borrowers through online platforms without the intermediation of any financial institutions (Lin et al. 2013; Greiner and Wang 2010; Sorbe 2009). Since the first P2P lending website, Zopa, established in U.K., P2P lending has spread all over the world, such as Prosper in U.S., Smava in Germany, Popfunding in Korea, and Ppdai in China. Prosper (https://www.prosper.com/) is one of the largest lending platforms in the world and had attracted 1.96 million registered members and had facilitated over $\$ 635$ million in loans by August 2013. Ppdai (http://www.ppdai.com/) is one of the largest lending platforms in China. By the end of August 2013, it had attracted over 500,000 registered members. To the end of 2014, there are 1575 P2P lending companies in China, and the total trading value is up to 25.28 billion Yuan (about 4 billion US\$).

Compared with traditional bank loans, P2P lending has its own features. Firstly, lenders make direct investments on the lending website, and they can learn the detailed information about online borrowers. So the information asymmetry is low in P2P lending. Secondly, the lending website provides a variety of functions that enable borrowers to indicate their creditability. It also provide functions for lenders to search loan request, do comparisons, and finally make a decision. So the open web platform actually observe the activities on both sides, say, the borrower side and the lender side. Collectively, it is presents a good opportunity to study the lending process. Thirdly, 
P2P borrower' credit is rated online. It relies on a large amount of web information and probably resort to data mining techniques. So the basic operation method in P2P lending is different from that in traditional bank loan.

Therefore, to develop a conceptual model for the P2P lending process is great valuable for managers tackling the issues on marketing, management and operation. In this paper, we will focus on the P2P lending process model and provide a comparative analysis compared with traditional bank loan process on both aspects of money flow and information flow.

The rest of the paper is organized as follows: Background study reviews relevant prior work on P2P lending. P2P lending process describes the P2P lending process. Finally, we discuss the findings and conclude the paper in Conclusions.

\section{Background study}

P2P lending model has attract great attentions from both industrial and academic fields. In the financial industry, P2P model provides a new pattern on group or crowd financial product design and management. For example, (Perlman 2012) propose an innovative group financial management system in his pattern (Chen and Han 2012) do a comparative study on P2P lending products between the USA and China. In the academic field, user behavior pattern and credit or trust model are inspect in the P2P lending scenario (Zhang et al. 2014; Klafft 2008; Herrero-Lopez 2009). For example, (Lee and Lee 2012) study the herding behavior in the P2P lending market where seemingly conflicting conditions and features of herding are present. They find strong evidence of herding and its diminishing marginal effect as bidding advances (Lin et al. 2013) find the online friendships of borrowers act as signals of credit quality. Friendships increase the probability of successful funding, lower interest rates on funded loans, and are associated with lower ex post default rates (Duarte et al. 2012) investigate the role appearance plays in financial transactions. They find that borrowers who appear more trustworthy have higher probabilities of having their loans funded. Moreover, borrowers who appear more trustworthy indeed have better credit scores and default less

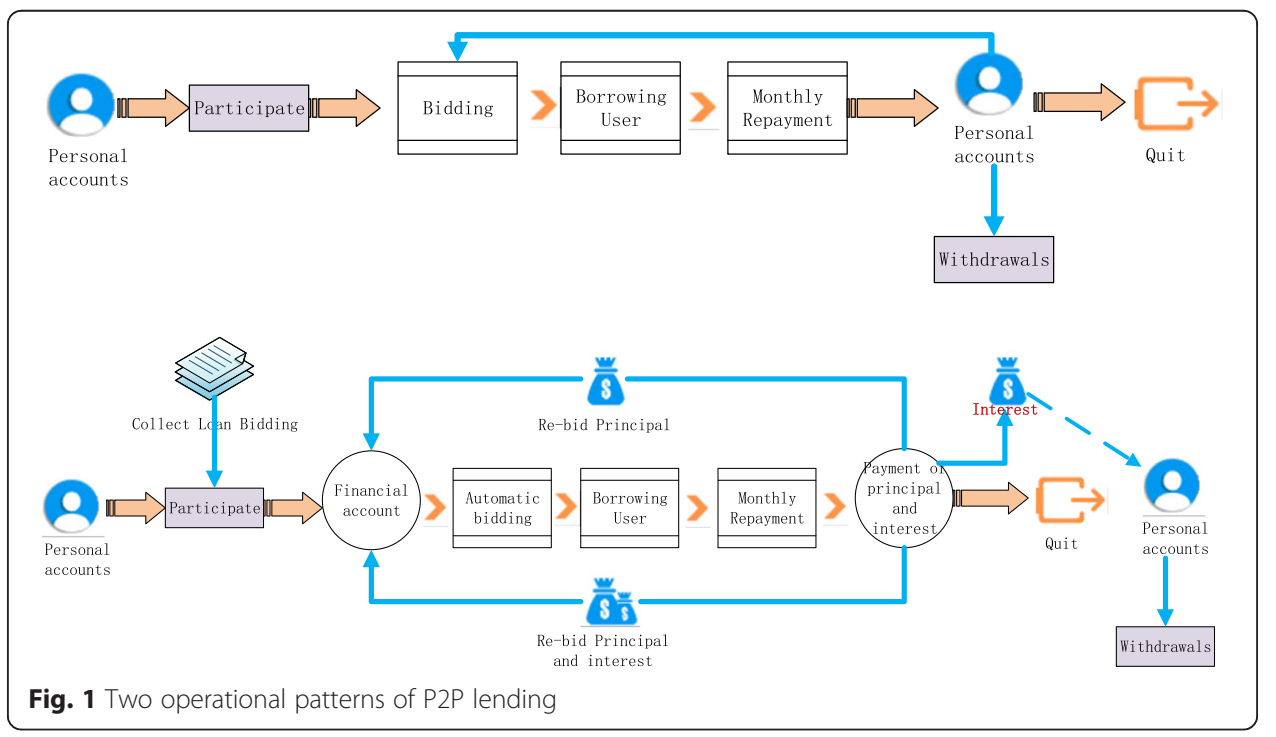




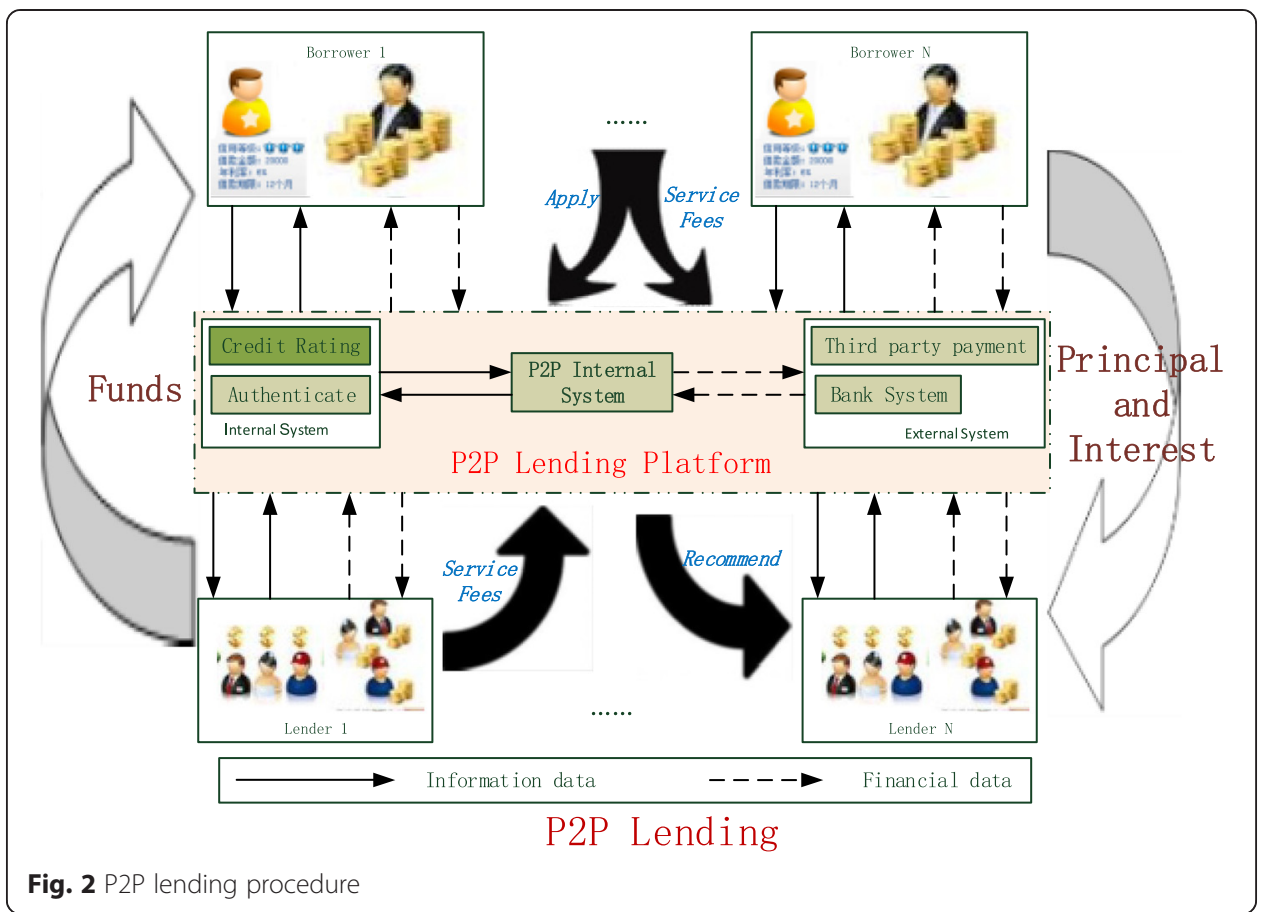

often. This research is quite similar to (Yang 2014), who use photographs in online P2P lending websites to study the transactional behaviors.

Process Model is a standard for business process modeling that provides a graphical notation for specifying business processes in a Business Process Diagram (BPD). The objective is to support business process management, for both technical users and business users, by providing a notation that is intuitive to business users (Wang et al. 2009) propose a novel methodology called Policy-Driven Process Mapping (PDPM) for extracting process models from business policy documents, it is the first systematic approach to the discovery of process models from business policies.

Therefore, different from previous studies which cover some particular aspects in P2P lending, we want to study P2P lending process model and how the data is flow in them. It would be great valuable to improve operations on a managerial level.

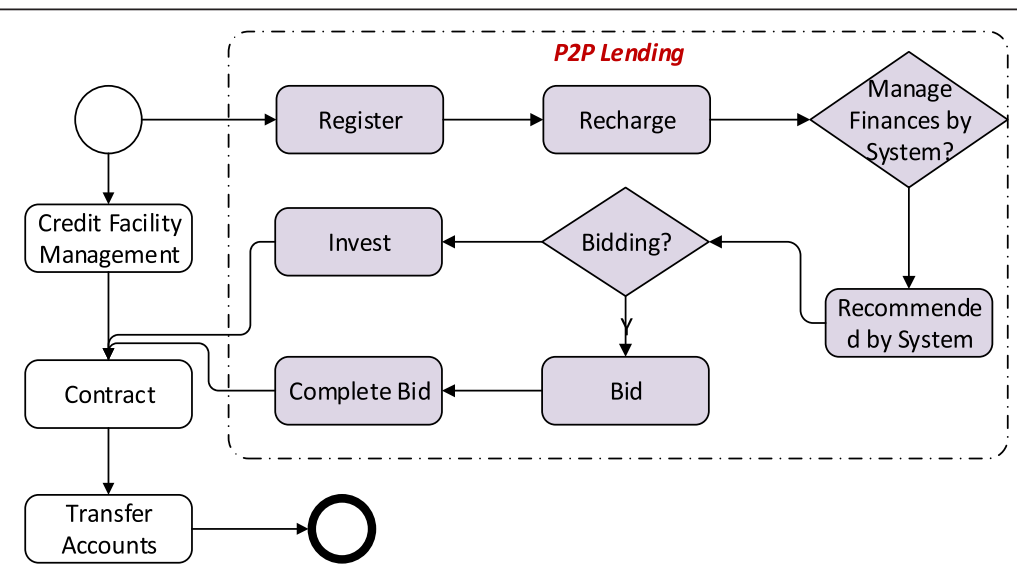

Fig. 3 Application process 


\section{Process comparisons between P2P lending and bank loan}

The main process of lending mechanism are almost the same across different online peer-to-peer lending platforms. Potential users, including borrowers and lenders first have to register with personal information, such as ID card number, bank account, personal information in a third-part credit institutions, etc. Based on these information, credit rating of users are calculated. The lending procedure is initialed by borrowers. Borrowers indicate the amount they want to borrow and the maximum rate they are willing to offer, and to provide some other optional information, such as loan purpose,

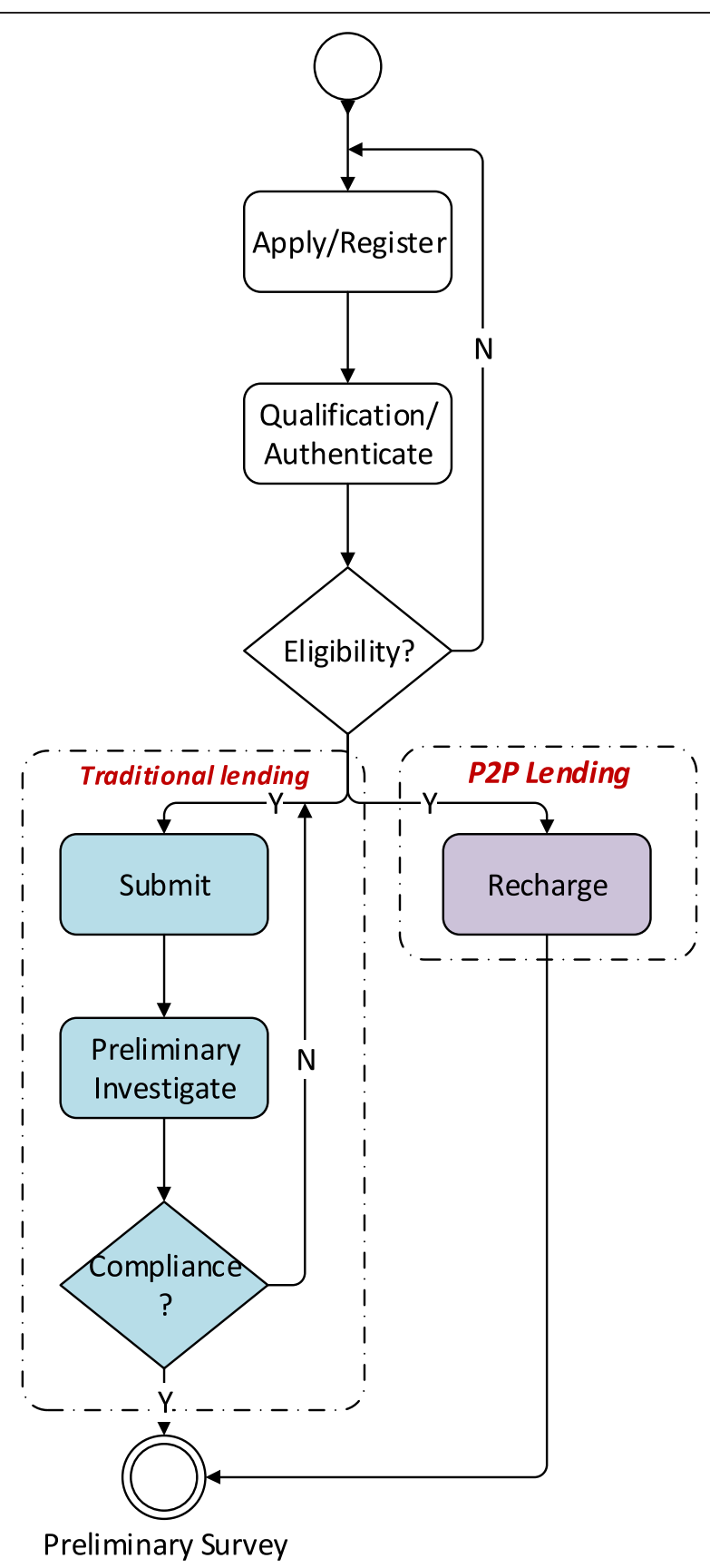

Fig. 4 Acknowledge process 
repayment period, listing auction format, etc. Lenders provide certain amount of money and choose a lending pattern. Currently, there are two patterns (As shown in Fig. 1). One pattern is the lender chooses a borrower on the platform, and borrow the money to him/ her. Another pattern is the lender puts money in a pool of funds. The P2P lending company dispatches the money to different borrowers. In this pattern, a lender doesn't know the borrower's information.

When a borrower's requirement is fully funded, the related transactions are send to the lending intermediary for further review before becoming a loan. In this stage, some additional documents may be asked for to demonstrate their credibility. Once a listing is materialized into a loan, money will be transferred from the accounts of listing lenders to the accounts of listing borrowers. The environment of P2P lending system is shown in Fig. 2.

To detailed investigate each stage of the procedure, we divide the whole process into 6 steps: application, acknowledge, credit, approval, assign and loan management. In the application process (Fig. 3), P2P lending is obviously need more information and operations compared with bank loan. One reason is P2P lending needs more information for credit audition. The other reason is P2P lending allows lenders to choose a borrower, so the information flow is more complex than bank loan.

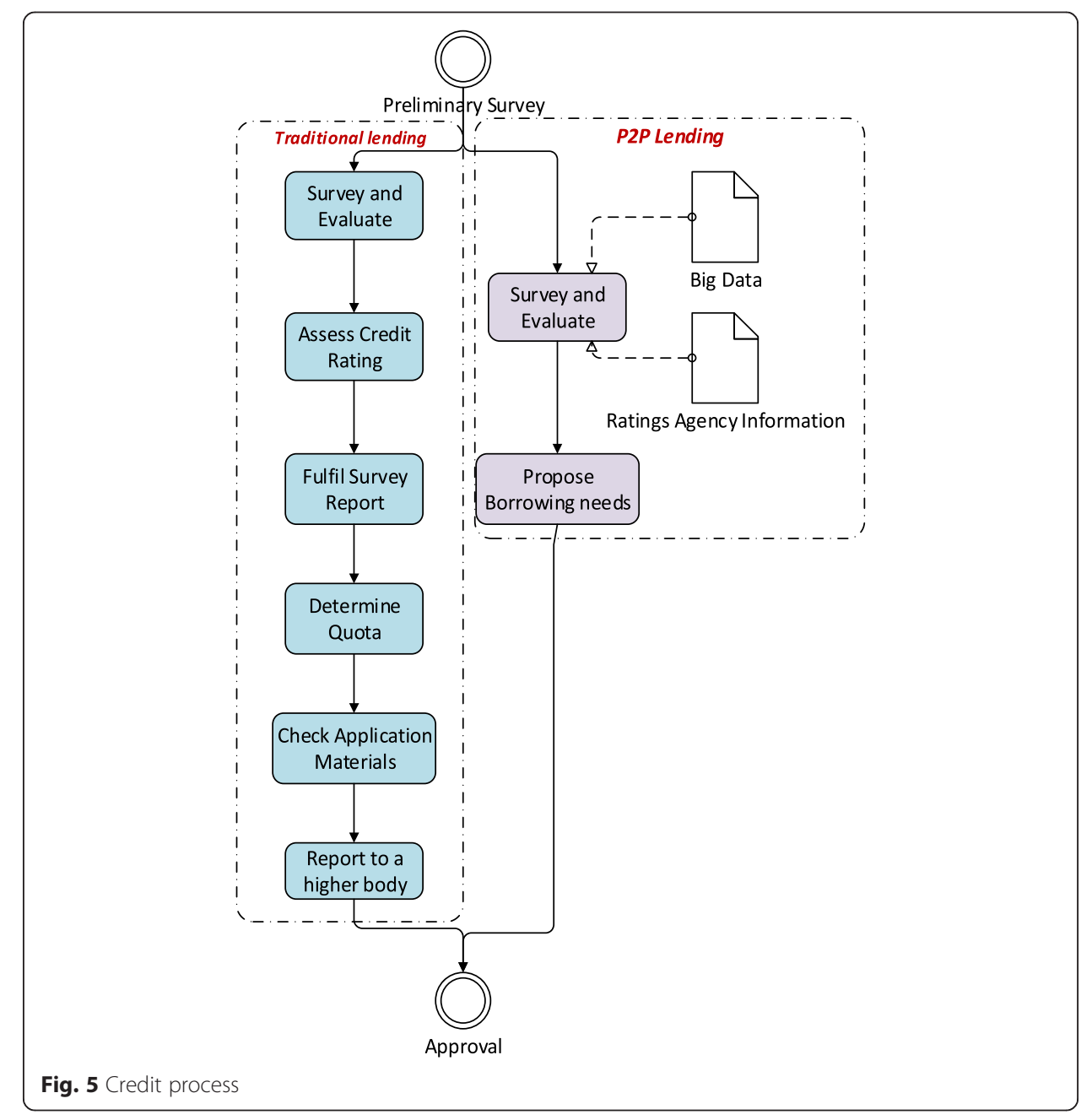



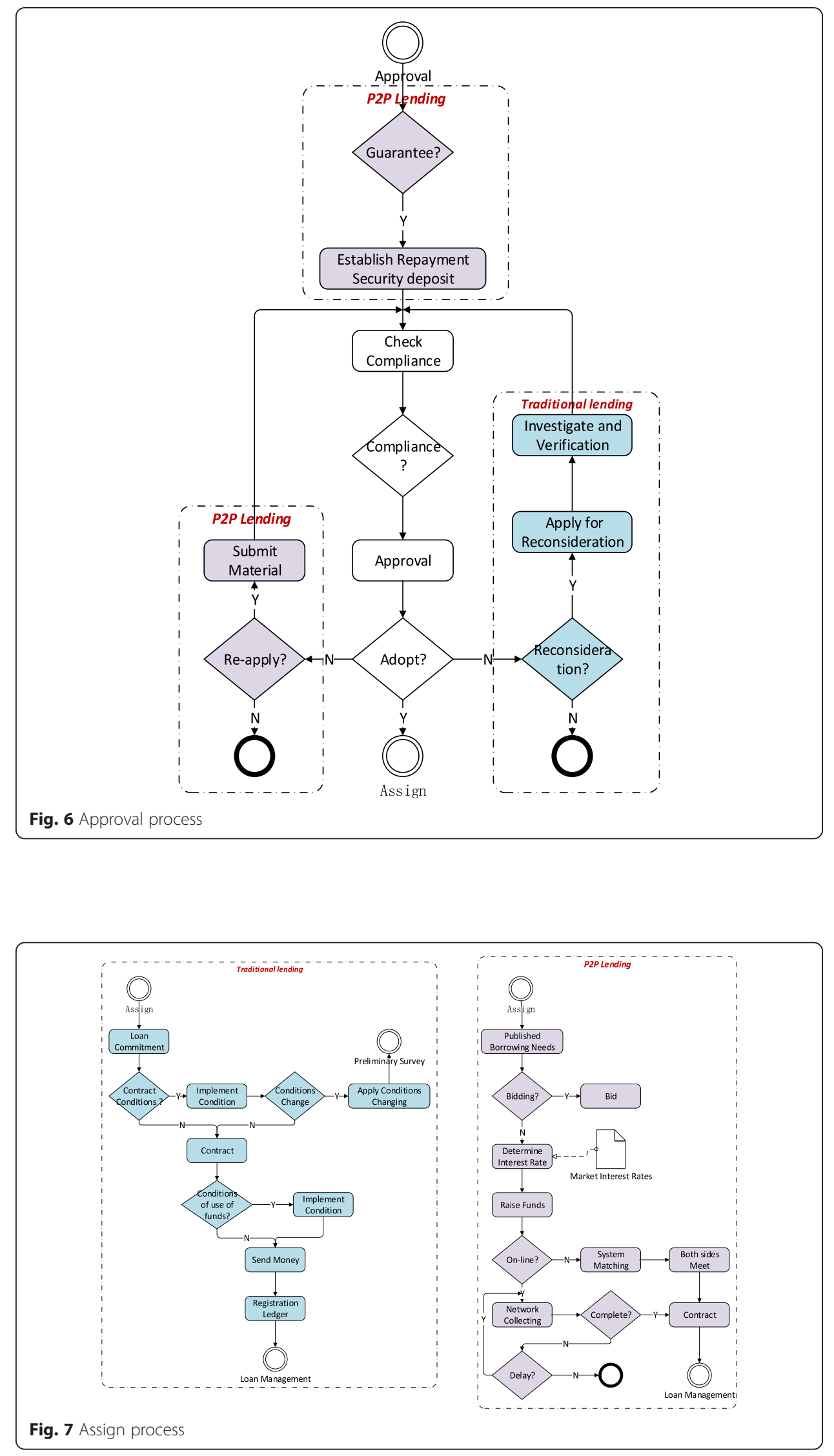
In the following acknowledge, credit and approval steps (Figs. 4, 5 and 6), the P2P lending process is much simpler than bank loan. This characteristic makes the P2P lending is much appeal to SME and personal borrowers, because they can provide little financial certificate and few mortgage assets. It should be noted that the credit analysis in P2P lending relies on users' information. So the credit method is different from bank.

The procedures of assign and loan management in P2P lending is quite different from bank loan (Figs. 7 and 8). In assign step, P2P is more complex than bank loan. This is because the rate is predefined in bank loan, but it is determined based on negotiations between borrowers and lenders in P2P lending. This flexible investment rate is a big progress on providing more marketed rate based on loan demands and requirements, and also attract customers. In the loan management step, bank is more complex than P2P lending, because it uses a standard process to ensure the loan is successful. P2P lending is emerging in this step, so many risks are there. For example, the information flow is suspend on investment failure, no more post-loan information is used to resolve the failure.

\section{Conclusions and future directions}

P2P lending is an innovation to traditional financial loan. In this paper, we compare the procedures between P2P lending and bank loan. We find that:

1. P2P lending provides users more privilege in choosing the lending manner and lending objects. So the information flow in P2P lending is more frequent and transparent.

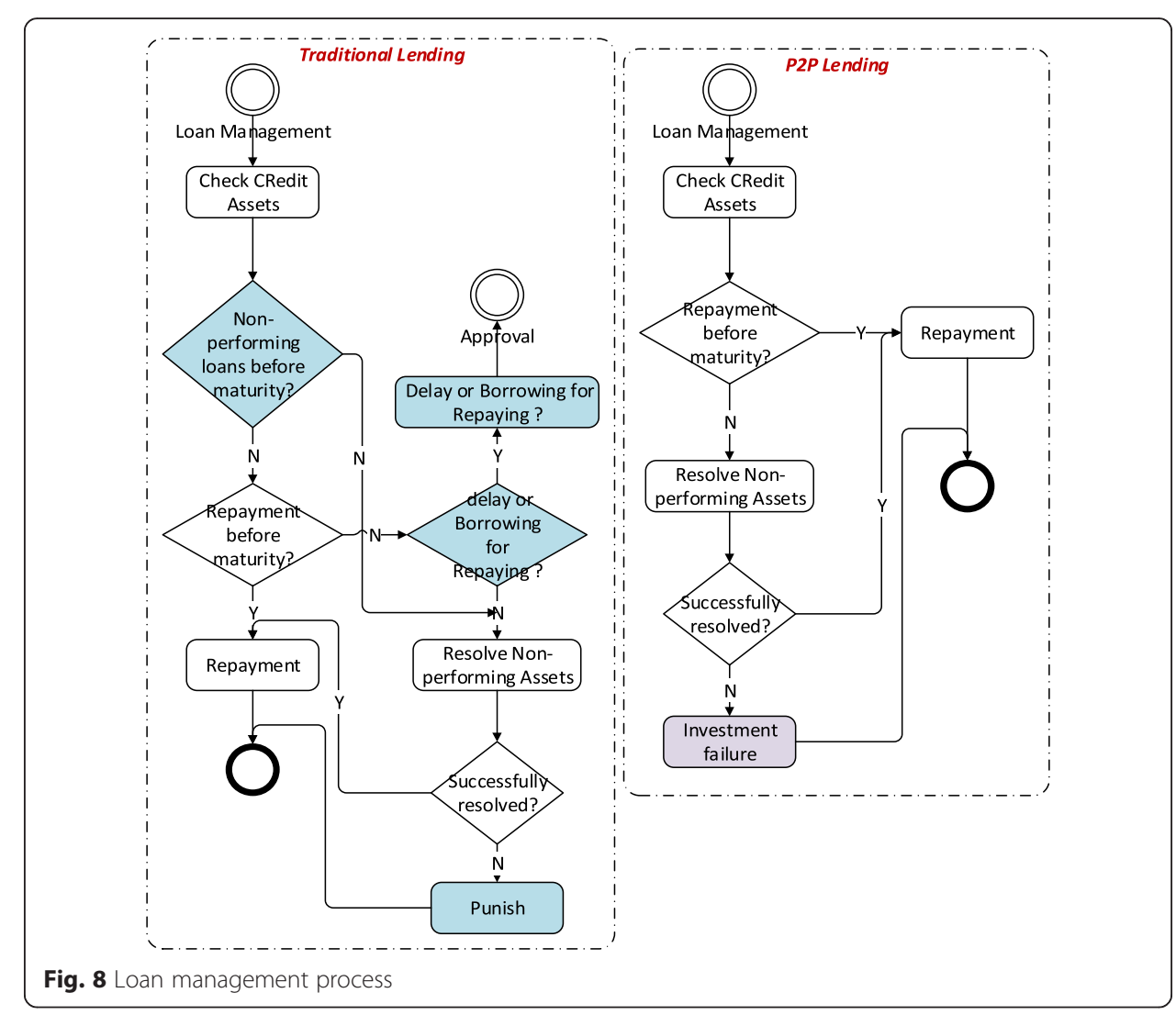


2. P2P lending uses a quite different credit audition method. It relies on information available in the system and the decision model. So IT techniques, e.g. big data analysis, data mining, on credit audition are key points in P2P lending.

3. The loan management is not very good in P2P lending, because it doesn't track the post-loan information on borrowers.

It is notable that we get these conclusions just from comparing the P2P lending process and traditional bank loan process. Further studies based on the process model include three directions. First, we want to formalize the P2P process model. Model formalization is valuable for process simulation and validation. Second, big data analysis techniques and models are needed to predict risk in credit audition. Third, the post-loan management is a critical problem in P2P lending process design.

Competing interests

The authors declare that they have no competing interests.

\section{Authors' contributions}

HW carried out the design of the study and coordination and draft the manuscript. KC participated in the research design and drafted the manuscript. WZ carried out the process comparison between P2P lending and bank loan. ZS participated in the sequence alignment. All authors read and approved the final manuscript.

\section{Acknowledgements}

The work described in this paper was partially supported by a grant from the Shenzhen Municipal Science and Technology R\&D Funding-Basic Research Program (Project No. JCYJ20140417105742712).

Received: 12 May 2015 Accepted: 12 May 2015

Published online: 09 June 2015

References

Berger SC, Gleisner F (2009) Emergence of financial intermediaries in electronic markets: the case of online P2P lending. BuR-Bus Res J 2(1):39-65

Chen D, Han C (2012) A comparative study of online P2P lending in the USA and China. J Internet Banking Commerce J 17(2):1-15

Duarte J, Siegel S, Young L (2012) Trust and credit: the role of appearance in peer-to-peer lending. Rev Financ Stud J 25(8):2455-2484

Greiner ME, Wang H (2010) Building consumer-to-consumer trust in e-finance marketplaces: an empirical analysis. Int J Electron Commerce J 15(2):105-136

Herrero-Lopez S (2009) Social interactions in P2P lending. In: Proceedings of the 3rd Workshop on Social Network Mining and Analysis, ACM, New York, NY, USA

Kiisel T (2013) Peer-to-peer loans. In: Getting a business loan, Springer, Berlin; pp 129-138

Klafft M (2008) Peer to peer lending: auctioning microcredits over the internet. In: Agarwal A, Khurana R (eds)

Proceedings of the International Conference on Information Systems, Technology and Management. IMT, Dubai, pp 1-8

Lee E, Lee B (2012) Herding behavior in online P2P lending: an empirical investigation. Electron Comm Res Appl J 11(5):495-503

Lin M, Prabhala NR, Viswanathan S (2013) Judging borrowers by the company they keep: friendship networks and information asymmetry in online peer-to-peer lending. Manage Sci J 59(1):17-35

Perlman JW (2012) Peer-to-peer and group financial management systems and methods: U.S. Patent No. 8280788. Available at http://www.google.com/patents/US8280788

Ppdai (2015) http://www.ppdai.com/

Prosper | Home (2015) https://www.prosper.com/

Sorbe T (2009) Person-to-person lending program product, system, and associated computer-implemented methods. U.S. Patent No. 20090228307. Available at http://www.google.com/patents/US20090228307

Wang $H$, Zhao $J$, Zhang $\sqcup$ (2009) Policy-Driven Process Mapping (PDPM): discovering process models from business policies. Decis Support Syst J 48(1):267-281

Yang X (2014) The role of photographs in online peer-to-peer lending behavior. Soc Behav Personal Int J 42(3):445-452

Zhang T, Tang M, Lu Y, Dong D (2014) Trust building in online peer-to-peer lending. J Global Inf Technol Manage J 17(4):250-266 